\author{
Alex Gnaegi \\ François Feihl \\ Olivier Boulat \\ Bernard Waeber \\ Lucas Liaudet
}

\section{Moderate hypercapnia exerts beneficial effects on splanchnic energy metabolism during endotoxemia}

Received: 28 October 2008

Accepted: 22 March 2009

Published online: 17 April 2009

(C) Springer-Verlag 2009

\section{A. Gnaegi · F. Feihl · B. Waeber ·}

L. Liaudet

Division of Clinical Pathophysiology and

Medical Teaching, Faculty of Biology and Medicine, University Hospital Center,

CHUV-BH 08-621, 1011 Lausanne,

Switzerland

\section{O. Boulat}

Central Laboratory of Clinical Chemistry, Faculty of Biology and Medicine, University Hospital Center, CHUV-BH 08-621, 1011 Lausanne, Switzerland

\section{Liaudet $(\square)$}

Department of Intensive Care Medicine, Faculty of Biology and Medicine, University Hospital Center, 1011 Lausanne, Switzerland e-mail: lucas.liaudet@chuv.ch

Tel.: +41-21-3140514

Fax: +41-21-3141384
Abstract Purpose: Low tidal volume ventilation and permissive hypercapnia are required in patients with sepsis complicated by ARDS. The effects of hypercapnia on tissue oxidative metabolism in this setting are unknown. We therefore determined the effects of moderate hypercapnia on markers of systemic and splanchnic oxidative metabolism in an animal model of endotoxemia. Methods: Anesthetized rats maintained at a $\mathrm{PaCO}_{2}$ of 30,40 or $60 \mathrm{mmHg}$ were challenged with endotoxin. A control group $\left(\mathrm{PaCO}_{2}\right.$ $40 \mathrm{mmHg}$ ) received isotonic saline. Hemodynamic variables, arterial lactate, pyruvate, and ketone bodies were measured at baseline and after $4 \mathrm{~h}$. Tissue adenosine triphosphate (ATP) and lactate were measured in the small intestine and the liver after 4 h. Results: Endotoxin resulted in low cardiac output, increased lactate/ pyruvate ratio and decreased ketone body ratio. These changes were not influenced by hypercapnia, but were more severe with hypocapnia. In the liver, ATP decreased and lactate increased independently from $\mathrm{PaCO}_{2}$ after endotoxin. In contrast, the drop of ATP and the rise in lactate triggered by endotoxin in the intestine were prevented by hypercapnia. Conclusions: During endotoxemia in rats, moderate hypercapnia prevents the deterioration of tissue energetics in the intestine.

Keywords ARDS · Sepsis · Hypercapnia - Mechanical ventilation $\cdot$ Energy metabolism

\section{Introduction}

Current recommendations for ventilatory support in patients with ARDS involve the use of small tidal volumes together with appropriate levels of end-expiratory positive pressure, in order to limit ventilator-induced lung injury. In most instances, the reduced minute ventilation associated with this "lung protective" strategy results in progressive hypercapnia [1]. It is a frequently held view that such "permissive" hypercapnia is generally well tolerated, but it is noticeable that only limited information is available regarding the proper pathophysiological effects of supranormal values of $\mathrm{PaCO}_{2}$ in this setting [2]. In particular, the influence of elevated $\mathrm{PaCO}_{2}$ on determinants of tissue oxygenation and energy metabolism has been only sparsely investigated so far [2]. This gap in knowledge is especially striking in the context of ARDS, which is frequently associated with sepsis [3]. According to our present understanding, tissue dysoxia represents a major factor in the development and the propagation of multiple organ dysfunction in sepsis [4]. Most notably, dysoxia in organs from the splanchnic territory is generally considered as a pivotal mechanism leading to multiple organ dysfunction [5], through various, yet 
incompletely understood, mechanisms. Thus, the interactions of sepsis, hypercapnia, and the gut-liver axis are of paramount clinical interest.

Importantly, a series of previous investigations indicated that hypercapnia might improve gut mucosal oxygenation in animals and humans under non-septic conditions $[6,7]$. We therefore stated the hypothesis that hypercapnia might ameliorate the status of tissue energy metabolism in the splanchnic territory in an animal model of endotoxemia, which reproduces some important pathophysiological aspects of sepsis. We have addressed this issue by investigating the influence of various $\mathrm{PaCO}_{2}$ levels on biochemical markers of oxidative metabolism, both at the systemic level and in splanchnic organs (liver and small intestine), in rats challenged with bacterial endotoxin and mechanically ventilated with various inspired fraction of $\mathrm{CO}_{2}$.

\section{Materials and methods}

Surgical preparation

All procedures were approved by the local animal experimentation committee, in accordance with the Swiss laws on animal experimentation. Twenty-eight male Wistar rats (320-400 g, mean weight $350 \mathrm{~g}$ ) were anesthetized with pentobarbital $(50 \mathrm{mg} / \mathrm{kg}$ intraperitoneally followed by an intravenous infusion at $10 \mathrm{mg} / \mathrm{kg} / \mathrm{h}$ ). The trachea was canulated for subsequent mechanical ventilation. Polyethylene catheters were inserted into the right femoral artery for the measurement of arterial blood pressure (BP) and heart rate (HR), and into the right femoral vein for intravenous infusions. A polyethylene catheter was inserted into the right internal jugular vein and a thermistor catheter was placed into the ascending thoracic aorta through the right carotid artery for the determination of cardiac output by transpulmonary thermodilution, as previously described [8]. Cardiac output was normalized to the weight of the animals to obtain cardiac index (CI). Arterial blood samples $(1 \mathrm{ml})$ were taken at baseline and at the end of experiments to measure plasma lactate, aceto-acetate and 3-hydroxybutyrate (see below). Additional blood samples $(75 \mu \mathrm{l})$ were taken hourly to measure arterial blood gases (AVL 940 blood gas analyzer; AVL Medical Instruments, Graz, Austria). The removed blood was replaced by equivalent volumes of isotonic saline.

Experimental protocol

\section{Mechanical ventilation}

Rats were allowed to stabilize for 20 min after surgery. Immediately after baseline measurements (T0), the animals were connected to a mechanical pressure controlled ventilator (Small animal ventilator 50-1916; Harvard Instruments, Edenbridge, UK) and paralyzed with a $1 \mathrm{mg} /$ $\mathrm{kg}$ i.v. bolus of pancuronium bromide, repeated when necessary to suppress spontaneous respiration. The tidal volume $\left(V_{\mathrm{t}}\right)$ and inflation pressure $\left(P_{\mathrm{i}}\right)$ were measured with a pneumotachograph (Fleisch No 4.0; Metabo, Epalinges, Switzerland) and a Bourdon manometer. Respiratory rate $\left(R_{\mathrm{r}}\right)$ was fixed at $80 / \mathrm{min}$, inspired fraction of oxygen $\left(\mathrm{FiO}_{2}\right)$ at 0.5 and $V_{\mathrm{t}}$ at $10 \mathrm{ml} / \mathrm{kg}$ to obtain in a few minutes a $\mathrm{PaCO}_{2}$ of $30 \pm 2 \mathrm{mmHg}$, as determined in preliminary experiments. A $5 \mathrm{ml} / \mathrm{kg} / \mathrm{h}$ infusion of isotonic saline was started and maintained until the end of experiment.

\section{Induction of hypercapnia}

In nonhypercapnic conditions, the animal was ventilated with a base gas mixture containing $50 \% \mathrm{O}_{2}$ and $50 \% \mathrm{~N}_{2}$. To induce hypercapnia ( $15 \mathrm{~min}$ after T0), pure $\mathrm{CO}_{2}$ was added to the inspiratory line by means of a rotameter, and initially titrated to achieve an $\mathrm{FiCO}_{2}$ of either 2 or $6 \%$ $( \pm 0.1 \%)$, as monitored by means of a $\mathrm{CO}_{2}$ analyzer (Servomex, UK). Subsequently, the rotameter setting was left unchanged, and the arterial $\mathrm{PCO}_{2}$ was kept in the desired range $(30,40$ or $60 \mathrm{mmHg}, \pm 5 \mathrm{mmHg}$ ) by adjusting $V_{\mathrm{t}}$ without exceeding a $P_{\mathrm{i}}$ of $18 \mathrm{~cm} \mathrm{H}_{2} \mathrm{O}$, or by adjusting $R_{\mathrm{r}}$ if necessary.

\section{Experimental groups}

The rats were allocated to one of four groups. One hour after baseline (T1), a $10 \mathrm{mg} / \mathrm{kg}$ intravenous challenge of endotoxin (lipopolyscharride-LPS) from Escherichia Coli (O127:B8; Sigma, Buchs, Switzerland) dissolved in $1 \mathrm{ml}$ isotonic saline was administered over $15 \mathrm{~min}$ in animals with a target $\mathrm{PCO}_{2}$ of $30 \mathrm{mmHg}$ (LPS 30 group, $n=8$ ), $40 \mathrm{mmHg}$ (LPS 40 group, $n=7$ ) and $60 \mathrm{mmHg}$ (LPS 60 group, $n=7$ ). A fourth group of rats, with $\mathrm{PaCO}_{2}$ controlled at $40 \mathrm{mmHg}$, did not receive LPS but an equivalent volume of saline only (control group, $n=6$ ). The animals were further observed during $3 \mathrm{~h}$, i.e. until the end of the fourth hour following baseline (T4).

\section{Biochemical measurements}

At the end of the experimental period, a quick laparotomy was performed in anesthetized animals. Biopsies from the jejunum and the liver were obtained and were immediately immersed into liquid nitrogen and stored at $-70^{\circ} \mathrm{C}$ until further processing. Rats were then killed by exsanguination. 


\section{Tissue ATP}

Tissue samples were powdered in liquid nitrogen, extracted in perchloric acid $2 \mathrm{~N}$, and adenosine triphosphate (ATP) was measured in the clear supernatants as described previously [9]. The tissue concentration of ATP was expressed in $\mu \mathrm{mol} / \mathrm{g}$ of tissue.

\section{Arterial ketone bodies ratio (AKBR)}

Arterial ketone bodies ratio was calculated as the molar ratio of acetoacetate/3-hydroxybutyrate, which estimates the NAD/NADH ratio, hence the redox state, of liver mitochondria [10]. One volume of whole blood was immediately deproteinized with one volume ice-cold perchloric acid $0.6 \mathrm{M}$. After centrifugation (15 min, $14,000 \mathrm{~g}$ ) supernatants were analyzed for 3-hydroxybutyrate and acetoacetate enzymatically with fluorimetric detection (excitation $340 \mathrm{~nm}$; emission $389 \mathrm{~nm}$ ) on a Cobas Fara fluorimeter (Roche Diagnostics, Basel, Switzerland).

\section{Lactate and pyruvate}

Lactate and pyruvate were determined in plasma and lactate was also measured in tissue extracts. For pyruvate measurement, sample $(50 \mu \mathrm{l})$ was added to a reaction mixture (pH 7.6, final volume $375 \mu \mathrm{l}$ ) containing at a final concentration lactate dehydrogenase $(>3.7 \mathrm{kU} / \mathrm{l}), \mathrm{NADH}$ $(0.23 \mathrm{mmol} / \mathrm{l})$, EDTA $(3.3 \mathrm{mmol} / \mathrm{l})$ and triethanolamine $(330 \mathrm{mmol} / \mathrm{l})$. The transformation of pyruvate to lactate with the consumption of NADH was measured at $340 \mathrm{~nm}$. L-Lactate was measured enzymatically using a lactate kit from Roche (Roche Diagnostics, Switzerland). The tissue concentration of lactate was expressed in $\mu \mathrm{mol} / \mathrm{g}$ tissue. In plasma, the ratio of lactate $(\mathrm{mM})$ to pyruvate $(\mathrm{mM})$ was calculated and expressed as the lactate to pyruvate $(\mathrm{L} / \mathrm{P})$ ratio.

\section{Statistical analysis}

Results are expressed as mean \pm SE mean of $n$ observations, where $n$ represents the number of animals studied. Repeated measures were analyzed by analysis of variance (ANOVA) for repeated measures. When appropriate, further comparisons were made for the effect of time using Dunnett's test, and for the effect of treatment using a modified Bonferroni adjustment (BonferroniHochberg) [11]. One-way ANOVA followed by Tukey test was used to compare values of tissue ATP and lactate concentrations between the groups. Statistics were performed using JMP IN software. Statistical significance was assigned to $P<0.05$.

\section{Results}

Arterial $\mathrm{PCO}_{2}, \mathrm{pH}$, and respiratory variables

The $\mathrm{PaO}_{2}$ was maintained above $95 \mathrm{mmHg}$ in all rats throughout the experiments. At baseline (T0), the $\mathrm{PaCO}_{2}$ was elevated in all groups due to the effect of anesthesia in spontaneously breathing animals. After initiation of mechanical ventilation, the desired level of $\mathrm{PaCO}_{2}$ was obtained in $30 \mathrm{~min}$ (Table 1). At $\mathrm{T} 1$, the ventilator settings were essentially identical between groups, indicating that the differences in $\mathrm{PaCO}_{2}$ were entirely due to the addition of $\mathrm{CO}_{2}$ to the inspired gas. In the $3 \mathrm{~h}$ following the bolus of endotoxin or saline, the $\mathrm{PaCO}_{2}$ was maintained within the target range. This required a slight increase in $V_{\mathrm{t}}$ and $R_{\mathrm{r}}$, with only minor differences between groups. $P_{\mathrm{i}}$ never exceeded $18 \mathrm{~cm} \mathrm{H}_{2} \mathrm{O}$ at any time (Table 2). Arterial $\mathrm{pH}$ was comparable in the four groups at T0 (Table 1). After $1 \mathrm{~h}$, it showed a significant increase in the rats ventilated at $\mathrm{PaCO}_{2} 30 \mathrm{mmHg}(P<0.05$ vs control and $P<0.05$ vs T0), while it decreased, albeit nonsignificantly, in rats ventilated at $60 \mathrm{mmHg}$. While $\mathrm{pHa}$ remained stable in the control group thereafter, it progressively and significantly decreased in the three groups of endotoxemic rats $(P<0.05$ vs control and $P<0.05$ vs T0 for all experimental groups). At T4, pHa was not statistically different between these three groups, while being significantly reduced in comparison with the control group.

\section{Hemodynamic data}

Table 1 shows the results of mean arterial blood pressure (mean BP), heart rate (HR) and cardiac index (CI) in the four groups of rats. Under baseline conditions and after $1 \mathrm{~h}$ (T0-T1), there were no statistically significant differences between the four groups for these different variables. Following LPS administration at T1, CI declined, so that at T3 and T4, CI was significantly smaller in all groups of LPS rats in comparison with baseline ( $P<0.05$ vs T0 for all LPS-treated groups). The reduction of CI was especially pronounced in the LPS 30 group. Indeed, at T4, CI was significantly lower in these rats when compared to both control and LPS 60 groups. All the other variables did not show any significant variations over the $4 \mathrm{~h}$ of the study, with no statistically significant changes between the four groups.

Plasma lactate, pyruvate and ketone bodies

As indicated in Fig. 1, lactate, pyruvate, and the lactate/ pyruvate ratio significantly increased after LPS $(P<0.05$ vs T0 and $P<0.05$ vs control). The increase in lactate and in the $\mathrm{L} / \mathrm{P}$ ratio was significantly more pronounced in 
Table 1 Time-course of arterial $\mathrm{PCO}_{2}$, arterial $\mathrm{pH}$ and hemodynamic variables

\begin{tabular}{|c|c|c|c|c|c|c|}
\hline Variable & Group & T0 & $\mathrm{T} 1$ & $\mathrm{~T} 2$ & $\mathrm{~T} 3$ & $\mathrm{~T} 4$ \\
\hline \multirow[t]{4}{*}{$\mathrm{PaCO}_{2}$} & Control & $52 \pm 2$ & $43 \pm 2 *$ & $41 \pm 23$ & $42 \pm 2^{*}$ & $43 \pm 2 *$ \\
\hline & LPS 30 & $51 \pm 2$ & $31 \pm 1 *^{\dagger}$ & $35 \pm 1 *^{\dagger}$ & $31 \pm 1 *^{\dagger}$ & $29 \pm 2 *^{\dagger}$ \\
\hline & LPS 40 & $50 \pm 2$ & $41 \pm 1^{*}$ & $44 \pm 2 *$ & $45 \pm 2 *$ & $41 \pm 4^{*}$ \\
\hline & LPS 60 & $57 \pm 2$ & $64 \pm 2^{* \dagger}$ & $68 \pm 2 *^{\dagger}$ & $68 \pm 2 *^{\dagger}$ & $63 \pm 2 *^{\dagger}$ \\
\hline \multirow[t]{4}{*}{$\mathrm{pHa}$} & Control & $7.31 \pm 0.01$ & $7.34 \pm 0.01$ & $7.33 \pm 0.01$ & $7.34 \pm 0.01$ & $7.35 \pm 0.02$ \\
\hline & LPS 30 & $7.33 \pm 0.02$ & $7.46 \pm 0.01 *^{\dagger}$ & $7.30 \pm 0.03$ & $7.25 \pm 0.03^{* \dagger}$ & $7.17 \pm 0.04 *$ \\
\hline & LPS 40 & $7.36 \pm 0.03$ & $7.38 \pm 0.01$ & $7.25 \pm 0.02 * \dagger$ & $7.23 \pm 0.01 *^{\dagger}$ & $7.17 \pm 0.02 *$ \\
\hline & LPS 60 & $7.31 \pm 0.02$ & $7.26 \pm 0.02$ & $7.18 \pm 0.01 *^{\dagger}$ & $7.14 \pm 0.01 *^{\dagger}$ & $7.11 \pm 0.03^{* \dagger}$ \\
\hline \multirow[t]{4}{*}{ Mean BP } & Control & $113 \pm 6$ & $118 \pm 7$ & $106 \pm 6$ & $108 \pm 5$ & $98 \pm 7$ \\
\hline & LPS 30 & $125 \pm 5$ & $129 \pm 2$ & $101 \pm 4$ & $112 \pm 5$ & $95 \pm 9$ \\
\hline & LPS 40 & $116 \pm 6$ & $125 \pm 4$ & $101 \pm 6$ & $112 \pm 3$ & $105 \pm 8$ \\
\hline & LPS 60 & $115 \pm 5$ & $125 \pm 4$ & $107 \pm 4$ & $109 \pm 4$ & $101 \pm 5$ \\
\hline \multirow{4}{*}{ HR } & Control & $391 \pm 15$ & $410 \pm 18$ & $384 \pm 21$ & $391 \pm 18$ & $390 \pm 23$ \\
\hline & LPS 30 & $408 \pm 17$ & $416 \pm 20$ & $449 \pm 22$ & $438 \pm 26$ & $392 \pm 22$ \\
\hline & LPS 40 & $401 \pm 16$ & $432 \pm 13$ & $430 \pm 14$ & $418 \pm 19$ & $403 \pm 16$ \\
\hline & LPS 60 & $405 \pm 15$ & $429 \pm 11$ & $429 \pm 14$ & $437 \pm 9$ & $393 \pm 19$ \\
\hline \multirow[t]{4}{*}{ CI } & Control & $197 \pm 13$ & $174 \pm 10$ & $151 \pm 6$ & $167 \pm 15$ & $168 \pm 22$ \\
\hline & LPS 30 & $210 \pm 13$ & $172 \pm 14$ & $164 \pm 11$ & $135 \pm 9 *$ & $96 \pm 9 * \dagger \S$ \\
\hline & LPS 40 & $187 \pm 13$ & $185 \pm 15$ & $161 \pm 9$ & $142 \pm 12 *$ & $125 \pm 12 *$ \\
\hline & LPS 60 & $217 \pm 13$ & $198 \pm 17$ & $197 \pm 10^{\dagger}$ & $171 \pm 12 *$ & $141 \pm 13^{*}$ \\
\hline
\end{tabular}

Rats were ventilated with $\mathrm{FiCO}_{2}$ of 0,2 or $6 \%$ to maintain a target $\mathrm{PaCO}_{2}$ of 30, 40 or $60 \mathrm{mmHg}$, and received either LPS or saline (control). After LPS, arterial $\mathrm{pH}$ decreased independently from the target $\mathrm{PaCO}_{2}$. There were no significant changes of blood pressure (BP, $\mathrm{mmHg}$ ) or heart rate (HR, beats per minute) over time. Cardiac index [CI, $\mathrm{ml} /(\mathrm{min} \mathrm{kg})]$ significantly decreased after 3 and $4 \mathrm{~h}$ in rats challenged with LPS, the change being significantly more pronounced in the LPS 30 group
Mean \pm SEM of $n=6$ (control), 8 (LPS 30) and 7 rats (LPS 40 and LPS 60)

* $P<0.05$ versus T0. ${ }^{\dagger} P<0.05$ versus control. ${ }^{\S} P<0.05$ versus LPS 60 (ANOVA followed by Dunnett for comparisons with T0, and by Bonferroni-Hochberg for comparisons between groups)

Table 2 Respiratory variables

\begin{tabular}{|c|c|c|c|c|c|c|}
\hline & \multicolumn{2}{|c|}{ Respiratory rate $\left(\min ^{-1}\right)$} & \multicolumn{2}{|c|}{ Tidal volume $(\mathrm{ml} / \mathrm{kg})$} & \multicolumn{2}{|c|}{ Inflation pressure $\left(\mathrm{cm} \mathrm{H}_{2} \mathrm{O}\right)$} \\
\hline & $\mathrm{T} 1$ & $\mathrm{~T} 4$ & $\mathrm{~T} 1$ & $\mathrm{~T} 4$ & $\mathrm{~T} 1$ & $\mathrm{~T} 4$ \\
\hline Control & $80 \pm 0$ & $81 \pm 2$ & $10.3 \pm 0.4$ & $10.8 \pm 0.4$ & $12.6 \pm 1.2$ & $16.1 \pm 1.8$ \\
\hline LPS 30 & $80 \pm 0$ & $82 \pm 4$ & $9.6 \pm 1.1$ & $10.1 \pm 1.1$ & $12.2 \pm 1.3$ & $15.2 \pm 0.8$ \\
\hline LPS 40 & $80 \pm 0$ & $83 \pm 4$ & $9.5 \pm 0.8$ & $9.9 \pm 0.8$ & $12.3 \pm 1.3$ & $16.4 \pm 1.0$ \\
\hline LPS 60 & $80 \pm 0$ & $85 \pm 4$ & $10.2 \pm 0.8$ & $10.7 \pm 0.6$ & $13.7 \pm 2.1$ & $17.1 \pm 0.9$ \\
\hline
\end{tabular}

Four groups of anesthetized rats were paralyzed and mechanically ventilated. $\mathrm{CO}_{2}(0,2$ and $6 \%)$ was added to the inhaled gas to reach pre-determined $\mathrm{PaCO}_{2}$ values of 30,40 and $60 \mathrm{mmHg}$, respectively. The rats were then challenged with LPS or saline (control group). The target $\mathrm{PaCO}_{2}$ was maintained by adjusting the respiratory rate or the tidal volume, without exceeding an inflation pressure of $18 \mathrm{~cm} \mathrm{H}_{2} \mathrm{O}$. No statistically significant differences were detected between groups for all variables

Mean \pm SD of $n=6$ (control), 8 (LPS 30) and 7 rats (LPS 40 and LPS 60) rats from the LPS 30 group. Regarding ketone bodies (Fig. 2), there were no significant differences in acetoacetate, 3-hydroxybutyrate and their ratio (AKBR) between groups at baseline. After 4 h, 3-hydroxybutyrate had significantly increased in the LPS 30 and LPS 40 $(P<0.05$ vs T0 and $P<0.05$ vs control), but not in the LPS 60 groups, whereas acetoacetate did not show significant alterations. In comparison to baseline, AKBR significantly diminished in the three groups of LPS rats $(P<0.05$ vs T0 and $P<0.05$ vs control for all
LPS-treated groups), but the change was significantly more pronounced in LPS 30 rats.

\section{Tissue ATP and lactate concentrations}

In the liver (Fig. 3), ATP significantly decreased and lactate significantly increased following LPS $(P<0.05$ vs control for all groups) without any influence of the various $\mathrm{PaCO}_{2}$ levels. In the small intestine (Fig. 4), when 

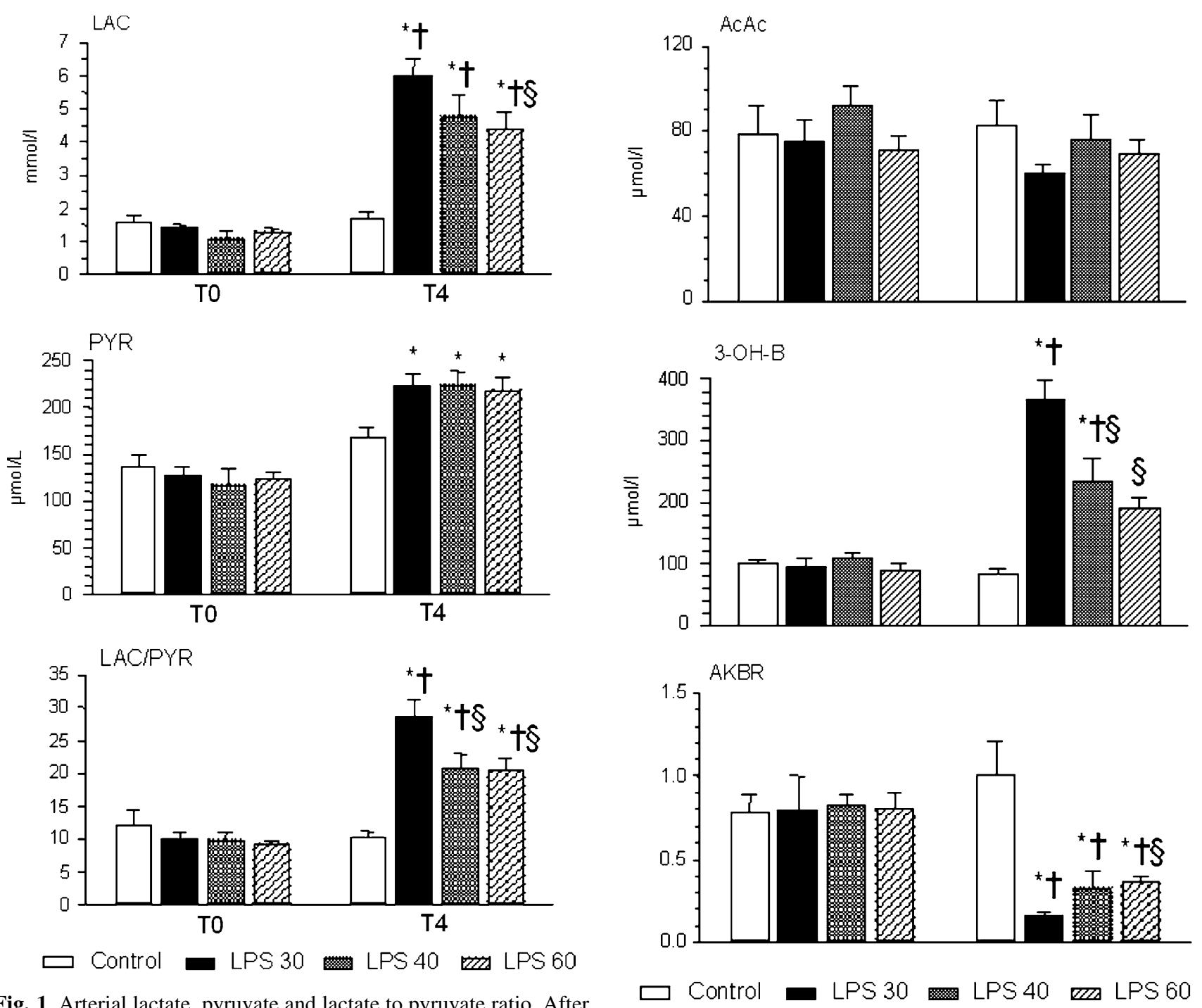

Fig. 1 Arterial lactate, pyruvate and lactate to pyruvate ratio. After $4 \mathrm{~h}(T 4)$, arterial lactate $(L A C)$, pyruvate $(P Y R)$ and the ratio lactate/pyruvate $(L A C / P Y R)$ were all significantly higher in the LPS groups, the changes being the most marked in the LPS 30 group. Mean \pm SEM of $n=6$ (control), 8 (LPS 30) and 7 rats (LPS 40 and LPS 60). ${ }^{*} P<0.05$ versus $T O .{ }^{\dagger} P<0.05$ versus control. ${ }^{\S} P<0.05$ versus LPS 30 (ANOVA followed by Dunnett for comparisons with $\mathrm{TO}$, and by Bonferroni-Hochberg for comparisons between groups)

compared to the value obtained in control rats $(2.1 \pm 0.1 \mu \mathrm{mol} / \mathrm{g})$, ATP was significantly reduced in the LPS $30(1.5 \pm 0.1 \mu \mathrm{mol} / \mathrm{g}, P<0.05 \mathrm{vs}$ control $)$ and LPS $40(1.7 \pm 0.2 \mu \mathrm{mol} / \mathrm{g}, P<0.05$ vs control $)$ groups. In contrast, ATP measured in the LPS 60 group $(1.9 \pm 0.1 \mu \mathrm{mol} / \mathrm{g})$ was not significantly different from the control group. Similarly, the intestinal lactate concentration was markedly increased in the LPS 30 and 40 groups $(P<0.05$ vs control), but was not statistically different from the controls in the LPS 60 group. Furthermore, the values of both ATP and lactate significantly differed between the LPS 60 and the LPS 30 groups.

Fig. 2 Plasma aceto-acetate, 3-hydroxybutyrate, and arterial ketone body ratio. No significant changes of plasma aceto-acetate $(A c A c)$ occurred in the four groups, whereas a significant increase in plasma 3-hydroxybutyrate $(3-\mathrm{OH}-\mathrm{B})$, together with a significant reduction of the arterial ketone body ratio $(A K B R)$ was noted after LPS, the change being significantly more pronounced in rats ventilated at a $\mathrm{PaCO}_{2}$ of $30 \mathrm{mmHg}$. Means \pm SEM of $n=6$ (control), 8 (LPS 30) and 7 rats (LPS 40 and LPS 60$)$. $* P<0.05$ versus T0. ${ }^{\dagger} P<0.05$ versus control. ${ }^{\S} P<0.05$ versus LPS 30 . (ANOVA followed by Dunnett for comparisons with T0, and by Bonferroni-Hochberg for comparisons between groups)

\section{Discussion}

Our study is the first to investigate the effects of various $\mathrm{PaCO}_{2}$ on biochemical parameters of energy metabolism during endotoxemia. The main novel finding is that hypercapnic acidosis has no negative impact on tissue energy metabolism, but rather improves it in the endotoxemic intestine, whereas moderate hypocapnia appears detrimental. These observations are particularly relevant 

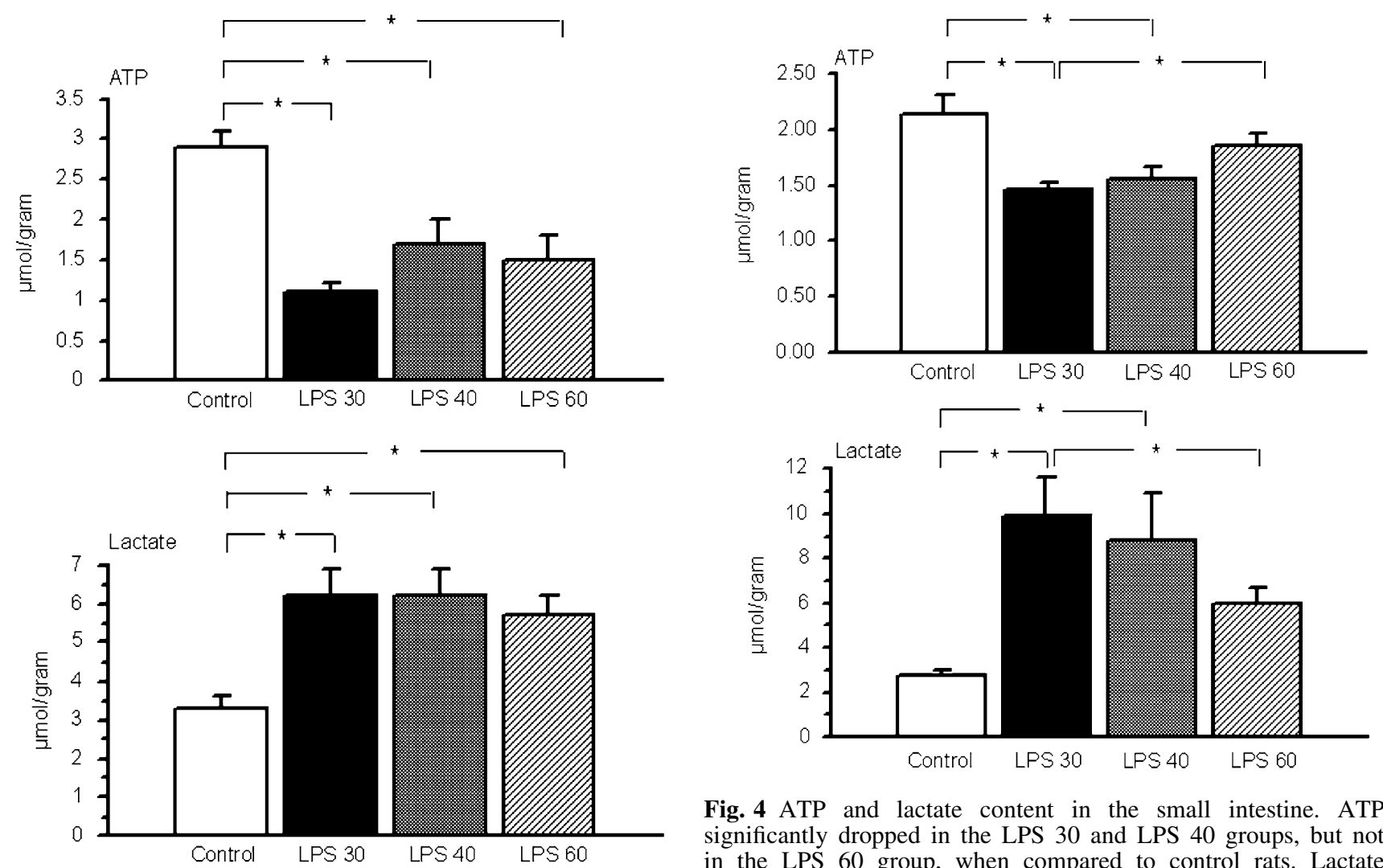

Fig. 4 ATP and lactate content in the small intestine. ATP significantly dropped in the LPS 30 and LPS 40 groups, but not in the LPS 60 group, when compared to control rats. Lactate significantly increased after LPS only in LPS 30 and LPS 40, but not in LPS 60 animals. Both ATP and lactate were significantly different between LPS 30 and LPS 60 . Mean \pm SEM of $n=6$ (control), 8 (LPS 30) and 7 rats (LPS 40 and LPS 60). ${ }^{*} P<0.05$ (ANOVA followed by Tukey)

to the pathophysiology of sepsis, given the key role played by disturbances in splanchnic oxygenation and energy metabolism in this setting.

Impaired cellular oxygenation and energetic failure, either ischemic or cytopathic in origin, represents a major mechanism of organ dysfunction in sepsis [4]. Accordingly, we found that endotoxin produced severe alterations in energy metabolism, indicated by lactic acidosis, reduced tissue ATP and increased tissue lactate in the gut and liver, as well as increased lactate/pyruvate ratio and decreased arterial ketone body ratio, in agreement with previous findings $[8,10,12]$. Since we did not measure tissue oxygen tensions, we can not conclude on the underlying mechanism (ischemic vs cytopathic), but we may speculate on a causal role of ischemic hypoxia, given the reduction of cardiac output triggered by endotoxin, and the supplydependent oxygen consumption that may occur in this setting [13]. It is noticeable that such reduction is a typical feature of this model of endotoxemia [14], which contrasts with the usually hyperdynamic circulation of sepsis.

Increasing $\mathrm{PaCO}_{2}$ from 40 to $60 \mathrm{mmHg}$ did not affect lactic acidosis and lactate/pyruvate ratio, indicating that moderate hypercapnia had no detrimental influence on

systemic tissue oxygenation. This is consistent with results recently reported by Wang et al. [15] in a model of sepsis in sheep, and this is also in line with the reported ability of hypercapnic acidosis to limit lactic acid production in physiological and pathological conditions [16]. Further, hypercapnia produced no changes on markers of hepatic energy metabolism (liver ATP and lactate, AKBR), consistent with the known fact that hypercapnia does not influence hepatic and splanchnic $V \mathrm{O}_{2}$ in animals [17] and humans [18]. In contrast, hypercapnia suppressed the fall in ATP and mitigated the increase in lactate in the gut, pointing to an improved balance between oxygen supply and metabolic needs in this organ. Since hypercapnia did not influence central hemodynamics, such effects can only be explained in terms of improved gut perfusion and local oxygen availability, and/or an improved cellular handling of oxygen, as discussed below. Of note, although hypercapnia is generally known to increase cardiac output via enhanced sympathetic tone, the absence of such an effect in our experiments may reflect the blunting of sympathetic reflexes due to barbiturate anesthesia [19], or to the direct effects of endotoxin [20]. 
The effects of hypercapnia on intestinal perfusion result from the balance between a direct local vasodilator effect and an indirect, sympatho-adrenergic, vasoconstrictor influence [2]. Depending on the conditions, hypercapnia has thus been associated with reduced [21], increased [22], or unchanged [23] gut perfusion. Although we did not measure regional perfusion, the influence of hypercapnia in the present study makes it unlikely that gut mucosal blood flow and oxygenation was jeopardized by the increased $\mathrm{PaCO}_{2}$. This contention would be consistent with previous results indicating that hypercapnia improves gut mucosal oxygenation in animals [6] and humans [7], and also with the beneficial effects of therapeutic hypercapnia reported in experimental mesenteric ischemia-reperfusion injury [24]. Thus, our current findings and those of the above-mentioned studies overall support the notion that moderate hypercapnia exerts a positive influence on intestinal oxygenation.

A second mechanism to discuss is a possible interference of $\mathrm{CO}_{2}$ with the development of cytopathic hypoxia, defined as a diminished production of ATP in the absence of cellular hypoxia [25]. A major mechanism of cytopathic hypoxia relies in the activation of the nuclear enzyme poly(ADP-ribose)-polymerase in response to DNA injury induced by oxidants such as peroxynitrite [25]. Theoretically, hypercapnia might affect these processes, given that $\mathrm{CO}_{2}$ may significantly alter the production, or the biological reactivity, of peroxynitrite [25].

At variance with hypercapnia, moderate hypocapnia $\left(\mathrm{PCO}_{2}=30 \mathrm{mmHg}\right)$ was detrimental to tissue energy metabolism, as evidenced by greater changes of plasma L/ $P$ ratio and AKBR, as well as larger reductions of ATP in the gut, which may reflect three known consequences of hypocapnia, that is, decreased blood flow, leftward shift in the oxyhemoglobin dissociation curve, or a lower intracellular $\mathrm{H}^{+}$concentration causing a reduced activity of pyruvate deshydrogenase [26, 27]. Importantly, several animal studies previously reported that hypocapnia could severely reduce blood flow to the liver [17] and the colonic mucosa [28]. Additional studies are clearly required to determine wether similar detrimental effects of hypocapnia may occur in patients as well.
Several limitations to our study deserve discussion. First, acute endotoxemia is a model of systemic inflammation whose clinical relevance is questionable, notably because it typically induces a pattern of hypodynamic shock with reduced cardiac output, contrasting with the typical hyperdynamic circulation of sepsis. However, it is noteworthy that therapeutic hypercapnia has also been associated with beneficial effects in experimental models of bacterial sepsis, induced by peritonitis [29] or pneumonia [30]. Second, we relied solely on ATP as an indirect marker of tissue energy metabolism. The cellular energy status is generally expressed by the combined ATP, ADP and AMP concentrations. In tissues, ADP and AMP consist of a bound and an unbound fraction, and only the free fractions are relevant for the energy status. Since the latter are extremely difficult to measure, we considered measuring ATP alone more accurate to reflect the cellular energetic status than a combination of ATP with total (i.e. bound and unbound fractions) of ADP and AMP, which are only partially energetically active [9]. Third, we did not evaluate whether changes in $\mathrm{PaCO}_{2}$ altered cell signal transduction in response to LPS, and whether such changes might have influenced our findings. Finally, our results have been obtained using a protocol of therapeutic hypercapnia induced by increased inspired fraction of $\mathrm{CO}_{2}$, which clearly differs from the clinical setting, in which hypercapnia results from decreased tidal ventilation [31].

In summary, our present data indicate that therapeutic hypercapnia has no deleterious effects on systemic and tissue markers of energy metabolism, but instead improves the energetic status of the intestine in endotoxemic conditions. In contrast, moderate hypocapnia may impair bioenergetics in this setting.

Acknowledgment This work was supported by grants from the Swiss National Fund for Scientific Research (PP00B-68882/1 and 320000/118174) to Lucas Liaudet.

Conflict of interest statement No author has any conflict of interest to disclose with respect to this work.

\section{References}

1. Antonelli M, Azoulay E, Bonten M, Chastre J, Citerio G, Conti G, De Backer D, Lemaire F, Gerlach H, Groeneveld J, Hedenstierna G, Macrae D, Mancebo J, Maggiore SM, Mebazaa A, Metnitz P, Pugin J, Wernerman J, Zhang H (2009) Year in review in Intensive Care Medicine, 2008: II. Experimental, acute respiratory failure and ARDS, mechanical ventilation and endotracheal intubation. Intensive Care Med 35:215-231
2. Akca O (2008) Carbon dioxide and tissue oxygenation: is there sufficient evidence to support application of hypercapnia for hemodynamic stability and better tissue perfusion in sepsis? Intensive Care Med 34:1752-1754

3. Jia X, Malhotra A, Saeed M, Mark RG, Talmor D (2008) Risk factors for ARDS in patients receiving mechanical ventilation for $>48 \mathrm{~h}$. Chest 133:853861
4. Carre JE, Singer M (2008) Cellular energetic metabolism in sepsis: the need for a systems approach. Biochim Biophys Acta 1777:763-771

5. Seguin P, Laviolle B, Guinet P, Morel I, Malledant Y, Bellissant E (2006) Dopexamine and norepinephrine versus epinephrine on gastric perfusion in patients with septic shock: a randomized study [NCT00134212]. Crit Care 10:R32 
6. Schwartges I, Schwarte LA, Fournell A, Scheeren TW, Picker O (2008) Hypercapnia induces a concentrationdependent increase in gastric mucosal oxygenation in dogs. Intensive Care Med 34:1898-1906

7. Fleischmann E, Herbst F, Kugener A, Kabon B, Niedermayr M, Sessler DI, Kurz A (2006) Mild hypercapnia increases subcutaneous and colonic oxygen tension in patients given $80 \%$ inspired oxygen during abdominal surgery. Anesthesiology 104:944-949

8. Rosselet A, Feihl F, Markert M, Gnaegi A, Perret C, Liaudet L (1998) Selective iNOS inhibition is superior to norepinephrine in the treatment of rat endotoxic shock. Am J Respir Crit Care Med 157:162-170

9. Liaudet L, Fishman D, Markert M, Perret C, Feihl F (1997) L-canavanine improves organ function and tissue adenosine triphosphate levels in rodent endotoxemia. Am J Respir Crit Care Med 155:1643-1648

10. Levy B, Mansart A, Bollaert PE, Franck P, Mallie JP (2003) Effects of epinephrine and norepinephrine on hemodynamics, oxidative metabolism, and organ energetics in endotoxemic rats. Intensive Care Med 29:292-300

11. Hochberg Y, Benjamini Y (1990) More powerful procedures for multiple significance testing. Stat Med 9:811818

12. Van Lambalgen AA, van Kraats AA, Mulder MF, Teerlink T, van den Bos GC (1994) High-energy phosphates in heart, liver, kidney, and skeletal muscle of endotoxemic rats. Am J Physiol 266:H1581-H1587

13. Tuchschmidt J, Oblitas D, Fried JC (1991) Oxygen consumption in sepsis and septic shock. Crit Care Med 19:664-671

14. Dyson A, Stidwill R, Taylor V, Singer M (2007) Tissue oxygen monitoring in rodent models of shock. Am J Physiol Heart Circ Physiol 293:H526-H533
15. Wang Z, Su F, Bruhn A, Yang X, Vincent JL (2008) Acute hypercapnia improves indices of tissue oxygenation more than dobutamine in septic shock. Am J Respir Crit Care Med 177:178183

16. Abu Romeh S, Tannen RL (1986) Amelioration of hypoxia-induced lactic acidosis by superimposed hypercapnea or hydrochloric acid infusion. Am J Physiol 250:F702-F709

17. Hughes RL, Mathie RT, Fitch W, Campbell D (1979) Liver blood flow and oxygen consumption during hypocapnia and IPPV in the greyhound. J Appl Physiol 47:290-295

18. Kiefer P, Nunes S, Kosonen P, Takala J (2001) Effect of an acute increase in $\mathrm{PCO} 2$ on splanchnic perfusion and metabolism. Intensive Care Med 27:775-778

19. Saha DC, Saha AC, Malik G, Astiz ME, Rackow EC (2007) Comparison of cardiovascular effects of tiletaminezolazepam, pentobarbital, and ketamine-xylazine in male rats. J Am Assoc Lab Anim Sci 46:74-80

20. Sayk F, Vietheer A, Schaaf B, Wellhoener P, Weitz G, Lehnert H, Dodt C (2008) Endotoxemia causes central downregulation of sympathetic vasomotor tone in healthy humans. Am J Physiol Regul Integr Comp Physiol 295:R891-R898

21. Abdel-Rassoul M, DeBellis J, Stein M (1977) Acute gastrointestinal bleeding during experimental hypercarbia. Chest 71:514-520

22. Fujita Y, Sakai T, Ohsumi A, Takaori M (1989) Effects of hypocapnia and hypercapnia on splanchnic circulation and hepatic function in the beagle. Anesth Analg 69:152-157

23. Salzman AL, Wang H, Wollert PS, Vandermeer TJ, Compton CC, Denenberg AG, Fink MP (1994) Endotoxin-induced ileal mucosal hyperpermeability in pigs: role of tissue acidosis. Am J Physiol 266:G633-G646
24. Laffey JG, Jankov RP, Engelberts D, Tanswell AK, Post M, Lindsay T, Mullen JB, Romaschin A, Stephens D, McKerlie C, Kavanagh BP (2003) Effects of therapeutic hypercapnia on mesenteric ischemia-reperfusion injury. Am J Respir Crit Care Med 168:13831390

25. Pacher P, Beckman JS, Liaudet L (2007) Nitric oxide and peroxynitrite in health and disease. Physiol Rev 87:315424

26. Raymer GH, Marsh GD, Kowalchuk JM, Thompson RT (2004) Metabolic effects of induced alkalosis during progressive forearm exercise to fatigue. J Appl Physiol 96:2050-2056

27. LeBlanc PJ, Parolin ML, Jones NL, Heigenhauser GJ (2002) Effects of respiratory alkalosis on human skeletal muscle metabolism at the onset of submaximal exercise. J Physiol 544:303-313

28. Gilmour DG, Douglas IH, Aitkenhead AR, Hothersall AP, Horton PW, Ledingham IM (1980) Colon blood flow in the dog: effects of changes in arterial carbon dioxide tension. Cardiovasc Res 14:11-20

29. Metzelder M, Kuebler JF, Shimotakahara A, Chang DH, Vieten G, Ure B (2008) CO2 pneumoperitoneum increases survival in mice with polymicrobial peritonitis. Eur J Pediatr Surg 18:171-175

30. Ni Chonghaile M, Higgins BD, Costello JF, Laffey JG (2008) Hypercapnic acidosis attenuates severe acute bacterial pneumonia-induced lung injury by a neutrophil-independent mechanism. Crit Care Med 36:31353144

31. Laffey JG, O'Croinin D, McLoughlin P, Kavanagh BP (2004) Permissive hypercapnia-role in protective lung ventilatory strategies. Intensive Care Med 30:347-356 